\title{
Natural history of pleural thickening after exposure to crocidolite
}

\author{
N H de KLERK, ${ }^{\text {W O C COOKSON, }}{ }^{2}$ A W MUSK, ${ }^{2}$ B K ARMSTRONG, ${ }^{1}$ J J GLANCY ${ }^{3}$ \\ From the National Health and Medical Research Council Unit in Epidemiology and Preventive Medicine,' \\ Department of Medicine, University of Western Australia, and the Departments of Respiratory Medicine ${ }^{2}$ and \\ Diagnostic Radiology, ${ }^{3}$ Sir Charles Gairdner Hospital, Perth, Western Australia
}

\begin{abstract}
Serial plain chest radiographs of 384 men who worked at the Wittenoom crocidolite mine and mill between 1943 and 1966 and who applied for pneumoconiosis compensation between 1948 and 1982 have been examined independently by two trained observers for pleural disease using the 1980 ILO-UICC classification of radiographs to record width and extent of pleural disease. Radiographs covering follow up periods of from two to 38 years were examined (median number of films per subject was nine). The degree of crocidolite exposure was estimated from employment records and a survey of airborne fibre concentrations performed in 1966. Agreement between the observers on the presence and degree of pleural disease in the final film for each subject was moderately close (Kendall's tau $B=0.62$ ) and was least for subjects with thickening $<5 \mathrm{~mm}$ in width. Diffuse pleural thickening extending for $>50 \%$ of the lateral chest wall was the most common type recorded by both observers. Minor pleural thickening frequently progressed in extent along the lateral chest wall but progression beyond $5 \mathrm{~mm}$ in thickness was less common. Pleural plaques were not seen to progress beyond their initial thickness or extent. The rate of onset of thickening in this population increased continually from the time of first exposure and also increased slightly with age. There was evidence that the level of total cumulative exposure to crocidolite increased the rate of onset of pleural thickening in the period between five and 15 years after first exposure. Rate of progression of established thickening was greatest in subjects who first developed thickening early after first exposure. The relative rate of progression decreased slowly with time from first signs of thickening and there was no evidence of any progression more than 15 years after onset.
\end{abstract}

Pleural thickening is a common result of asbestos exposure and appears as either circumscribed plaques on the parietal pleura or as diffuse pleural thickening affecting both parietal and visceral pleura. ${ }^{1}$ It is also seen in urban dwellers without a known history of either industrial or environmental exposure to asbestos fibres ${ }^{23}$ and is more common in communities surrounding industries that make much use of asbes$\operatorname{tos}^{45}$ or where there are natural deposits of asbestos or related minerals. ${ }^{6}$ It also occurs commonly among household contacts of asbestos workers. ${ }^{7}$ Diffuse pleural thickening found without a history of either industrial or environmental exposure to asbestos fibres $^{23}$ may be due to prior pleural injury or inflammation, but because most surveys are based on existing $x$ ray series of self selected subjects, estimates

Accepted 18 July 1988 of this proportion-for example, about $5 \%$ in the British Thoracic and Tuberculosis Association survey $^{3}$ - will usually be too large. Indeed a recent United States study used the prevalence of pleural thickening as an index of prior asbestos exposure, ignoring other possible causes. ${ }^{8}$

The nature of the dependency of pleural thickening on the degree of asbestos exposure is unclear. Many studies have found an association between time since first exposure or age and the prevalence of plaques and thickening ${ }^{9-13}$ but only one has shown any additional relation with level of exposure. ${ }^{10} \mathrm{~A}$ recent review concluded that plaques occur earlier in more heavily exposed subjects but this has never been adequately demonstrated. ${ }^{12}$ There are no data relating fibre type to the occurrence of pleural thickening.

Diffuse pleural thickening is associated with varying degrees of lung function impairment, ${ }^{14-17}$ although, except in severe cases, the effect is considered to be 
only slight unless there is accompanying parenchymal involvement. ${ }^{1218}$ Given similar degrees of exposure, parenchymal involvement is more likely to occur among men with plaques than among those without. ${ }^{19}$ The relation of pleural plaques or diffuse pleural thickening to subsequent development of malignancy is not clear. ${ }^{1420}$

Little is known about the usual course of pleural plaques or diffuse pleural thickening. Anecdotal evidence indicates that diffuse thickening, which sometimes follows the occurrence of benign pleural effusions, may be progressive. ${ }^{1821}$

The former workers at the mine and mill at Wittenoom Gorge, Western Australia, offer a unique opportunity to study serial changes in pleural disease caused by exposure to crocidolite. Many of these men who were exposed to high concentrations of asbestos fibres for relatively short periods have had no other occupational exposure to asbestos and have had repeated chest radiographs performed subsequently. The Wittenoom mine and mill were operated by a single company between 1943 and 1966. The employment records of the company have been retained and form the basis of a continuing mortality study. ${ }^{223}$ The present study is based on serial radiographic data accumulated over four decades on those subjects from this workforce who made an initial claim to the Pneumoconiosis Medical Board of Western Australia for compensation for asbestosis between 1948 and 1982.

\section{Subjects}

A total of 384 men who had worked at Wittenoom applied for compensation for asbestosis between 1948 and December 1982. Plain chest radiographs were recovered for 303 of these subjects, providing follow up periods of between two and 38 years from the start of exposure to asbestos. Between one and 27 (median 9) radiographs were located and examined for each subject.

\section{Methods}

Work histories of the subjects were obtained from employment records of the company and supplemented by records of subscribers to a benevolent fund (The Western Australian Mine Workers Relief Fund). Additional data were obtained from records of subjects presenting themselves for compulsory chest $x$ ray examinations at the Perth Chest Clinic. The concentrations of airborne respirable fibres of crocidolite $>5$ microns in length were measured in various workplaces in a survey of the industry undertaken on behalf of the Mines Department of Western Australia in $1966 .{ }^{24}$ de Klerk, Cookson, Musk, Armstrong, Glanc $\overline{\bar{B}}$

Plain chest radiographs were sought from the Pert度 Chest Clinic and Perth teaching hospitals where the majority of subjects applying for pneumoconiosit. compensation had been seen. All radiographs were classified for pleural and parenchymal diseas independently by two experienced observers (AWM? and JJG) according to the 1980 ILO Classification of Radiographs of Pneumoconioses. ${ }^{25}$ They were rea\& side by side in known temporal order, withou出 knowledge of exposure or compensation details, and pleural disease was coded according to the stage of disease as follows: $0=$ absence of thickening; stages 1-3 had $<5 \mathrm{~mm}$ thickening extending over less than quarter, a quarter to a half, or more than half of the lateral chest wall respectively; stages $4-6$ and 7-9 corresponded to $5-10 \mathrm{~mm}$ and $>10 \mathrm{~mm}$ thickeninक respectively, with the same three extent categories. For the purpose of this study a "plaque" or "localise 6 pleural thickening" was taken as thickening extending for less than one quarter of the length of the laterap chest wall and of greater than $5 \mathrm{~mm}$ in thickness-that is, stages 4 and 7 -although the ILO classification makes no distinction between plaques and diffuse thickening.

The results were analysed separately for each readefo and observer agreement was assessed by Kendall's tat B statistic. To allow for the fact that these data were haphazard with respect to the times at which the $x$ ras studies were performed, to retain information on th: maximum number of subjects and to use a slightls more tractable model than we have used previously, $\frac{26}{7}$ each subject's follow up period was grouped into sis five year intervals up to 30 years after first employment at Wittenoom and one interval after 30 years. Thu each man could have data for up to seven periods included up until the end of his follow up (date of permanent departure or death or 31 December 1982) If no radiograph was found for a period he was. excluded from that period and the subsequent one.

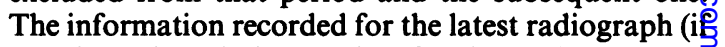
any) in each period was taken for the analysis. It was classified for degree of pleural thickening as: the same as, greater than, or not known, in comparison with the latest radiograph from the previous period. $A$. stratified Poisson regression model was used to assesड్ the effect of certain factors on the rate of getting worse. ${ }^{27}$ This assumed that covariates act multio plicatively on the underlying incidence or hazard ratê which is constant within each five year period anฐ which therefore has to be estimated before estimatin the covariate effects. For those with no thickening® getting worse implied onset of the disease and for those with some thickening it meant progression (of thicken $\frac{}{2}$ ing or extent) of the disease. Covariates examine were: degree of pleural thickening seen on the previouß $x$ ray film (no thickening, some thickening, or noß 
Table 1 Characteristics of subjects with and without radiographs available for study

\begin{tabular}{|c|c|c|c|}
\hline & $\begin{array}{l}\text { With } \\
\text { radiographs } \\
(n=303)\end{array}$ & $\begin{array}{l}\text { Without } \\
\text { radiographs } \\
(n=81)\end{array}$ & $p^{*}$ \\
\hline \multicolumn{4}{|c|}{$\begin{array}{l}\text { Mean calendar year of } \\
\text { birth } \\
\text { Mean calendar year of }\end{array}$} \\
\hline $\begin{array}{l}\text { starting work } \\
\text { Mean age started work } \\
\text { Mean calendar year of }\end{array}$ & $\begin{array}{l}1955 \\
32 \cdot 9\end{array}$ & $\begin{array}{l}1953 \\
39 \cdot 1\end{array}$ & $\begin{array}{r}0.0007 \\
<0.0001\end{array}$ \\
\hline $\begin{array}{l}\text { application for } \\
\text { compensation } \\
\text { No of days worked } \dagger \\
\text { Intensity of exposure: }\end{array}$ & $\begin{array}{r}1968 \\
545\end{array}$ & $\begin{array}{r}1967 \\
724\end{array}$ & $\begin{array}{l}0.68 \\
0.13\end{array}$ \\
\hline \multicolumn{4}{|c|}{ Total cumulative exposure: } \\
\hline Fibre/cc yearst & $22 \cdot 1$ & $26 \cdot 4$ & 0.60 \\
\hline
\end{tabular}

${ }^{*} p$ Values for difference between subjects with and without radiographs (Student's $t$ test or Chi squared test).

†Geometric mean values.

known), follow up time from onset of exposure (as defined above), follow up time from onset of pleural thickening, intensity of exposure to crocidolite, duration of exposure, total cumulative exposure, place of work (mill or elsewhere), year of birth, and year of starting work.

\section{Results}

There were large differences in age at starting work, year of birth, and year of starting work between the 81 subjects for whom no radiograph could be located and the 303 subjects for whom radiographs were found (table 1). These differences indicate a greater success in retrieval of films performed more recently. There were no appreciable differences in measures of exposure to crocidolite between these two groups of subjects. In those subjects with some radiographs retrieved, reader 1 found that 170 (56\% of subjects) and reader 2 that $137(45 \%)$ eventually developed some radiographic evidence of pleural thickening.
Table 2 Inter-observer agreement on stage of pleural thickening in the most recent chest radiograph of each person

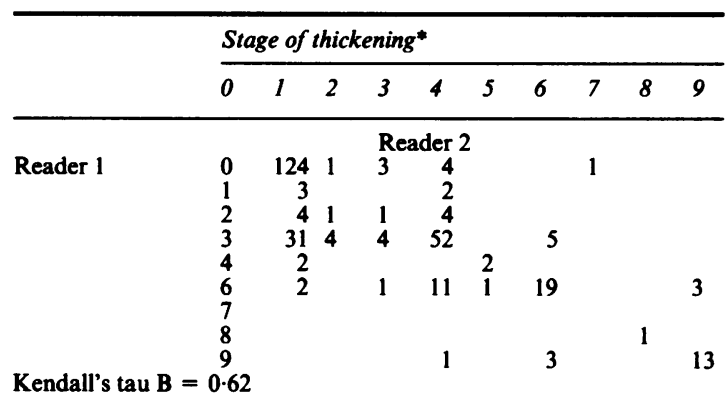

*Stage: $0=$ absence of thickening; stages 1-3 had $<5 \mathrm{~mm}$ thickening extending over $<0.25,0.25-0.5$, or $>0.5$ of the lateral chest wall respectively; stages $4-6$ and 7-9 corresponded to $5-10 \mathrm{~mm}$ and $>10 \mathrm{~mm}$ thickening respectively, with the same three extent categories.

Agreement between observers for each subject's final film gave a value for Kendall's tau B statistic of 0.62 (table 2). This indicates moderately close agreement between observers. Disagreement was greatest in subjects considered to have thickening of $<5 \mathrm{~mm}$ extending over more than half of the lateral chest wall. Despite these differences the results of separate analyses for the two observers were similar so that only those for reader 1 are presented.

Diffuse pleural thickening was observed much more frequently than pleural plaques (localised pleural thickening) by both observers (table 2). The most common type of thickening at all times since first employment was diffuse pleural thickening extending for more than $50 \%$ of the lateral chest wall (stages 3,6, and 9 , table 3 ). Thickening of less than $5 \mathrm{~mm}$ (stage 3) was observed more often than thickening of 5-10 mm (stage 6), which was in turn observed more often than thickening of greater than $10 \mathrm{~mm}$ (stage 9). Pleural plaques were not seen to progress beyond their initial stage of thickening or extent along the chest wall.

Table 3 Relation between stage of pleural thickening and years since first employed (reader I)

\begin{tabular}{|c|c|c|c|c|c|c|c|}
\hline \multirow[b]{2}{*}{ Stage of thickening* } & \multicolumn{7}{|c|}{ Years since first employed } \\
\hline & $0-5$ & $5-10$ & $10-15$ & $15-20$ & $20-25$ & $25-30$ & $>30$ \\
\hline $\begin{array}{l}\text { None } \\
1 \\
2 \\
3 \\
4 \\
6 \\
8 \\
9 \\
\text { No of } x \text { ray films retrieved } \\
\text { Total No of subjects at risk }\end{array}$ & $\begin{array}{r}225 \\
2 \\
3 \\
1 \\
1 \\
1 \\
0 \\
0 \\
151 \\
384\end{array}$ & $\begin{array}{r}138 \\
3 \\
10 \\
12 \\
2 \\
1 \\
0 \\
1 \\
211 \\
384\end{array}$ & $\begin{array}{r}109 \\
7 \\
9 \\
37 \\
2 \\
6 \\
0 \\
1 \\
185 \\
378\end{array}$ & $\begin{array}{r}86 \\
7 \\
17 \\
54 \\
3 \\
12 \\
1 \\
4 \\
131 \\
356\end{array}$ & $\begin{array}{r}43 \\
3 \\
10 \\
56 \\
2 \\
22 \\
1 \\
10 \\
70 \\
315\end{array}$ & $\begin{array}{r}29 \\
1 \\
1 \\
38 \\
0 \\
18 \\
0 \\
7 \\
29 \\
218\end{array}$ & $\begin{array}{r}11 \\
0 \\
0 \\
21 \\
0 \\
12 \\
0 \\
4 \\
0 \\
123\end{array}$ \\
\hline
\end{tabular}

*See footnote to table 2 . 


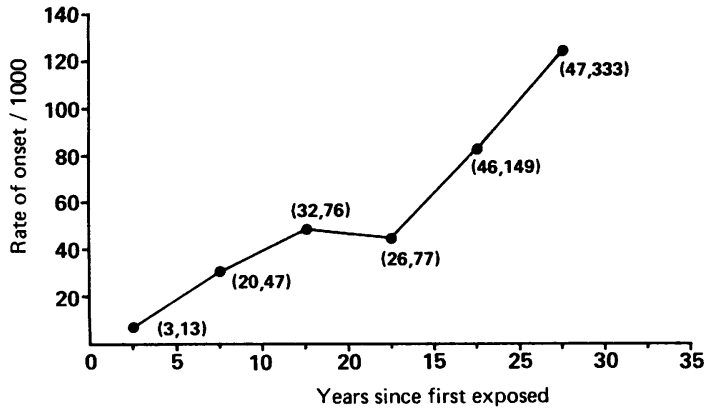

Fig 1 Rate of onset of diffuse pleural thickening per 1000 person-years by time since first employed at Wittenoom ( $95 \%$ confidence interval).

Allowing for exclusions in periods when no radiographs were found, there were 2777 person-years of observation for onset of disease with 79 events and 638 person-years of observation for progression of disease with 26 events. The rate of onset of pleural thickening increased steadily from first exposure to crocidolite (fig 1). The rate of progression in thickness or extent of pleural thickening, or both, was greater in subjects who first developed thickening soon after first being exposed to crocidolite than in those in whom thickening developed in later years (fig 2). The rate of progression was highest in the five year period immediately after it appeared and fell slowly with time thereafter (fig 3). There was no evidence of progression occurring more than 15 years after onset of the disease.

Linear trend lines fitted all three sets of data almost as well as terms for the individual periods. They showed approximately a $63 \%$ increase in the incidence rate and a $32 \%$ fall in rate of progression for each five year period since first exposure and a $22 \%$ fall in rate of progression for each five year period since onset.

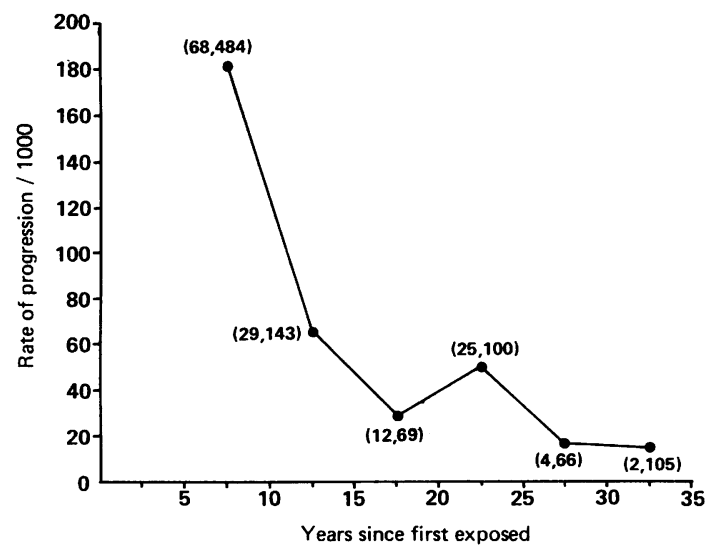

Fig 2 Rate of progression of diffuse pleural thickening per 1000 person-years by time since first employed at Wittenoom $(95 \%$ CI).

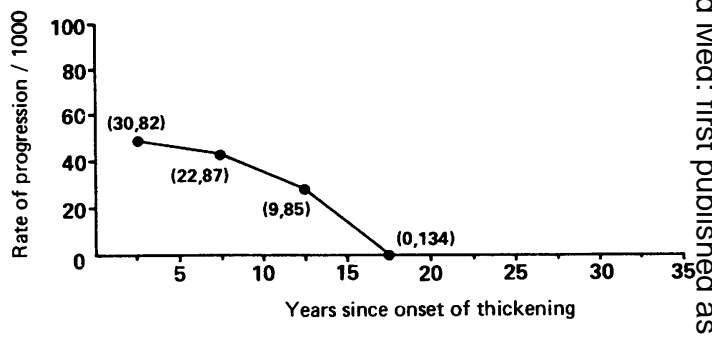

Fig 3 Rate of progression of diffuse pleural thickening per $\vec{\circ}$ 1000 person-years by time since onset of thickening $195 \%$ CI).

The effect of time from onset of exposure on progresฐ sion was not significant when added to a model alreadx containing time since first exposure $(p=0.95)$ and showed no decline at all.

Table 4 shows the relative risks of onset of thicken? ing in categories of each covariate added individuall $\Phi$ to a model already containing terms for the categories. of time since first exposed shown in fig 1 . No large or consistent effects were found for any of the covariates Similarly there appeared to be no substantial effect of any exposure variable on the rate of progressiog (table 5).

Because it had been suggested that more heavilo exposed people may experience pleural thickenin earlier than others ${ }^{12}$ the effect of the interaction of tota cumulative exposure with time since exposure on onsep of the disease was examined. Although the addition of all the terms was not significant $\left(\chi^{2}{ }_{s}=7 \cdot 6, p=0 \cdot 18\right.$ the individual terms confirmed this proposition (table 6), with significant effects of total cumulative exposure on onset of pleural thickening increasing the rate about $20 \%$ per $\log$ (fibre/cc year) between five and $1 \delta$ years after first employment but not at other times There were not sufficient data to test the linearity of these effects within periods.

\section{Discussion}

This study shows that radiographic evidence of pleura disease was common in subjects applying for pneumoconiosis compensation who were previous $\overline{\bar{y}}$ exposed to crocidolite asbestos at Wittenoom. Diffuse pleural thickening was seen much more often thatp pleural plaques and nearly $70 \%$ of the subjects showed evidence of pleural thickening observed by one of other reader. It first appeared up to 30 years after onsey of exposure to asbestos and the incidence increased steadily with time after first exposure. There was evidence that the rate of onset of pleural thickening was greater in subjects with heavier exposure tō crocidolite. The subsequent rates of progression of extent and thickness of pleural thickening were greatest in subjects who developed thickening earf 
Table 4 Effects of exposure related variables on the rate of onset of diffuse pleural thickening

\begin{tabular}{|c|c|c|c|c|c|}
\hline \multirow[b]{2}{*}{ Variable* } & \multirow[b]{2}{*}{ No of subjectst } & \multirow[b]{2}{*}{ Rate ratio } & \multirow[b]{2}{*}{$95 \% C I$} & \multicolumn{2}{|l|}{ p Value $\ddagger$} \\
\hline & & & & Categories & Trend \\
\hline $\begin{array}{l}\text { Total cumulative expos } \\
<1 \\
1-9.99 \\
10-49.99 \\
50-99.99 \\
\geqslant 100\end{array}$ & $\begin{array}{l}\text { c years): } \\
19 \\
35 \\
69 \\
48 \\
71\end{array}$ & $\begin{array}{l}1.0 \\
1.6 \\
1.9 \\
1.5 \\
1.5\end{array}$ & $\begin{array}{l}0 \cdot 6,4 \cdot 3 \\
0 \cdot 7,4 \cdot 8 \\
0 \cdot 6,3 \cdot 9 \\
0 \cdot 6,3 \cdot 6\end{array}$ & 0.75 & 0.76 \\
\hline $\begin{array}{l}\text { Year of first exposure: } \\
1943-9 \\
1950-6 \\
\geqslant 1957\end{array}$ & $\begin{array}{r}16 \\
114 \\
112\end{array}$ & $\begin{array}{l}1.0 \\
1.3 \\
1.6\end{array}$ & $\begin{array}{l}0 \cdot 5,3 \cdot 4 \\
0 \cdot 6,4 \cdot 1\end{array}$ & 0.58 & $0 \cdot 32$ \\
\hline $\begin{array}{l}\text { Duration of exposure: } \\
0-3 \text { months } \\
3-6 \text { months } \\
6 \text { months- } 2 \text { years } \\
2-5 \text { years } \\
>5 \text { years }\end{array}$ & $\begin{array}{l}30 \\
16 \\
62 \\
84 \\
50\end{array}$ & $\begin{array}{l}1.0 \\
1.5 \\
1.6 \\
1.9 \\
1.3\end{array}$ & $\begin{array}{l}0 \cdot 5,4 \cdot 3 \\
0 \cdot 7,3 \cdot 6 \\
0 \cdot 9,4 \cdot 1 \\
0 \cdot 6,2 \cdot 9\end{array}$ & 0.51 & 0.44 \\
\hline $\begin{array}{l}\text { Intensity of exposure (f } \\
0-9.99 \\
10-19.99 \\
20-49.99 \\
\geqslant 50\end{array}$ & $\begin{array}{l}45 \\
59 \\
91 \\
47\end{array}$ & $\begin{array}{l}1.0 \\
1.4 \\
1.6 \\
1.2\end{array}$ & $\begin{array}{l}0.7,2.9 \\
0.8,3.0 \\
0.5,2.7\end{array}$ & 0.51 & 0.42 \\
\hline $\begin{array}{l}\text { Site of work: } \\
\text { Ever in mill } \\
\text { Never in mill }\end{array}$ & $\begin{array}{r}55 \\
187\end{array}$ & $\begin{array}{l}1.0 \\
1.0\end{array}$ & $0 \cdot 6,1 \cdot 7$ & 0.99 & \\
\hline $\begin{array}{l}\text { Age at radiograph }(y): \\
0-39 \\
40-49 \\
50-59 \\
\geqslant 60\end{array}$ & $\begin{array}{r}104 \\
78 \\
37 \\
23\end{array}$ & $\begin{array}{l}1.0 \\
1.3 \\
1.1 \\
1.8\end{array}$ & $\begin{array}{l}0 \cdot 7,2 \cdot 4 \\
0 \cdot 5,2 \cdot 3 \\
0 \cdot 8,4 \cdot 1\end{array}$ & 0.49 & 0.29 \\
\hline
\end{tabular}

*Variables: categories of exposure and age for each subject within each five year period calculated at the date of the $x$ ray examination. † Numbers of subjects: categories of exposure and age for each subject at the time of their last $x$ ray examination.

¡p Values for significance of all categories separate or a single trend variable.

after onset of crocidolite exposure. Once thickening was observed the rate of progression across the categories of the ILO Classification ${ }^{25}$ fell steadily with time.

Although reader 2 recorded diffuse pleural thickening less often than reader 1 the differences in interpretation did not affect the main findings of the study. Disagreement between the observers was greatest for subjects considered to have pleural thickening $<5 \mathrm{~mm}$ in thickness and extending for more than half the lateral chest wall. This degree of disagreement is not surprising given the difficulties in differentiating true mild pleural thickening from companion shadows, subpleural fat, and muscle insertions on the plain chest radiograph. Mild diffuse pleural thickening may also be mistaken for subpleural parenchymal fibrosis on the chest radiographs and any exposure effects result from such misclassification. This seems unlikely, however, given the total contrast of these results with those found for the same group of men when relating exposure with onset and progression of parenchymal fibrosis, ${ }^{26}$ where progression but not onset was shown to be related to exposure.
Total cumulative exposure had a significant effect on the rate of onset in the five to 15 year period after first employment but not thereafter. This means that during this period those with greater exposure were more likely to develop thickening and as a group would therefore have had a shorter mean time to onset than those with lesser exposure. This supports other evidence showing earlier onset for more heavily exposed individuals. ${ }^{12}$ The lack of an effect in the first five years could imply that incidence in this period is due to other causes than exposure to asbestos at work. The lack of a detectable effect of the level of asbestos exposure on the rate of onset after 15 years could perhaps help to explain why other studies have failed to show a relation between the prevalence of diffuse pleural thickening in asbestos workers and the total amount of asbestos inhaled. ${ }^{1121}$ It had been thought that duration of exposure may have been confounded with the effect of time since first exposure in these other populations who had continuing low grade exposure ${ }^{12}$ rather than a short period of intense exposure as experienced by workers from Wittenoom.

There was no evidence that intensity and duration 
Table 5 Effects of exposure related variables on the rate of progression of diffuse pleural thickening

\begin{tabular}{|c|c|c|c|c|c|}
\hline \multirow[b]{2}{*}{ Variable* } & \multirow{2}{*}{$\begin{array}{l}\text { No of subjects } \\
\text { with thickening }\end{array}$} & \multirow[b]{2}{*}{ Rate ratio } & \multirow[b]{2}{*}{$95 \% C I$} & \multicolumn{2}{|l|}{ p Value $\ddagger$} \\
\hline & & & & Categories & Trend \\
\hline $\begin{array}{l}\text { Total cumulative exposu } \\
<1 \\
1-9.99 \\
10-49.99 \\
50-99.99 \\
\geqslant 100\end{array}$ & $\begin{array}{l}\text { c years): } \\
5 \\
11 \\
16 \\
15 \\
20\end{array}$ & $\begin{array}{l}1.0 \\
0.9 \\
0.2 \\
0.4 \\
0.5\end{array}$ & $\begin{array}{l}0 \cdot 2,4 \cdot 6 \\
0 \cdot 0,1 \cdot 6 \\
0 \cdot 1,2 \cdot 5 \\
0 \cdot 1,2 \cdot 7\end{array}$ & 0.34 & 0.48 \\
\hline $\begin{array}{l}\text { Year of first exposure: } \\
1943-9 \\
1950-6 \\
\geqslant 1957\end{array}$ & $\begin{array}{r}5 \\
33 \\
29\end{array}$ & $\begin{array}{l}1 \cdot 0 \\
0 \cdot 6 \\
0 \cdot 4\end{array}$ & $\begin{array}{l}0 \cdot 1,2 \cdot 8 \\
0 \cdot 1,2 \cdot 2\end{array}$ & $0 \cdot 39$ & $0 \cdot 16$ \\
\hline $\begin{array}{l}\text { Duration of exposure: } \\
0-3 \text { months } \\
3-6 \text { months } \\
6 \text { months }-2 \text { years } \\
2-5 \text { years } \\
>5 \text { years }\end{array}$ & $\begin{array}{r}7 \\
5 \\
14 \\
24 \\
17\end{array}$ & $\begin{array}{l}1.0 \\
1.2 \\
0.8 \\
0.7 \\
0.8\end{array}$ & $\begin{array}{l}0 \cdot 2,6 \cdot 2 \\
0 \cdot 2,3 \cdot 2 \\
0 \cdot 2,2 \cdot 9 \\
0 \cdot 2,3 \cdot 2\end{array}$ & 0.94 & 0.57 \\
\hline $\begin{array}{l}\text { Intensity of exposure (fit } \\
0-9.99 \\
10-19.99 \\
20-49.99 \\
\geqslant 50\end{array}$ & $\begin{array}{l}11 \\
15 \\
30 \\
11\end{array}$ & $\begin{array}{l}1.0 \\
0.9 \\
1 \cdot 3 \\
1.2\end{array}$ & $\begin{array}{l}0 \cdot 2,4 \cdot 1 \\
0 \cdot 4,4 \cdot 6 \\
0 \cdot 3,5 \cdot 0\end{array}$ & 0.92 & 0.53 \\
\hline $\begin{array}{l}\text { Site of work: } \\
\text { Ever in mill } \\
\text { Never in mill }\end{array}$ & $\begin{array}{l}17 \\
50\end{array}$ & $\begin{array}{l}1 \cdot 0 \\
1.2\end{array}$ & $0 \cdot 5,3 \cdot 1$ & 0.63 & \\
\hline $\begin{array}{l}\text { Age at radiography }(y) \text { : } \\
0-39 \\
40-49 \\
50-59 \\
\geqslant 60\end{array}$ & $\begin{array}{r}2 \\
17 \\
25 \\
23\end{array}$ & $\begin{array}{l}1.0 \\
0.3 \\
0.9 \\
1.0\end{array}$ & $\begin{array}{l}0 \cdot 1,1 \cdot 5 \\
0 \cdot 2,3 \cdot 8 \\
0 \cdot 2,4 \cdot 4\end{array}$ & 0.16 & 0.27 \\
\hline
\end{tabular}

*Variables: categories of exposure and age for each subject within each five year period calculated at the date of the $x$ ray examination. tNumbers of subjects: categories of exposure and age for each subject at the time of their last $x$ ray examination.

$\ddagger p$ Values for significance of all categories separate or a single trend variable.

of exposure to asbestos, or any other exposure related variables, affected the rate of progression of pleural thickening, but given the comparatively small numbers of subjects progressing, the power of this study to detect effects on progression is much less than that for detecting effects on onset.

Increasing numbers of subjects previously exposed to crocidolite at Wittenoom Gorge may be expected to develop diffuse pleural thickening but on present evidence it appears unlikely that it will progress sufficiently to cause impairment of lung function in the

Table 6 Effects of total cumulative exposure on the rate of onset of pleural thickening at different times after first employment

\begin{tabular}{lll}
\hline Time from first employment $(y)$ & Rate ratio $^{*}$ & $95 \%$ CI \\
\hline$<5$ & 0.84 & $0.68,1.02$ \\
$5-10$ & 1.16 & $1.08,1.24$ \\
$10-15$ & 1.23 & $1.15,1.31$ \\
$15-20$ & 1.03 & $0.74,1.44$ \\
$20-25$ & 0.97 & $0.65,1.46$ \\
$25-30$ & 1.04 & $0.73,1.48$ \\
$\geqslant 30$ & 1.00 & $0.10,9.74$ \\
\hline
\end{tabular}

* Rate ratio per unit increase in $\log$ (fibres/ml years). absence of parenchymal fibrosis or the occurrence of pleural effusion.

The help of Dr J Cassidy and the staff of the Perth Chest Clinic, the staff of the radiology department at the Sir Charles Gairdner Hospital, and Miss E Bingle is gratefully acknowledged.

\section{References}

1 Hillerdal G. Non-malignant asbestos pleural disease. Thorax 1981;36:669-75.

2 Albelda SM, Epstein DM, Gefter WB, Miller WT. Pleural $N$ thickening: its significance and relationship to asbestos dust exposure. Am Rev Respir Dis 1982;126:621-4.

3 British Thoracic and Tuberculosis Association and the Medical $O$ Research Council Pneumoconiosis Unit. A survey of pleural thickening: its relation to asbestos exposure and previous pleural disease. Environ Res 1972;5:142-51.

4 Andrion A, Colombo A, Dacorsi M, Mollo F. Pleural plaques at autopsy in Turin. A study on 1019 adult subjects. Eur J Respir Dis 1982;63:107-12.

5 Navratil $M$, Trippe $F$. Prevalence of pleural calcification in $\frac{}{\mathbb{D}}$ persons exposed to asbestos dust, and in the general population $\stackrel{\square}{\square}$ in the same district. Environ Res 1972;5:210-6. 
6 Rohl AN, Langer AM, Moncure G, Selikoff IJ, Fischbein A. Endemic pleural disease associated with exposure to mixed fibrous dust in Turkey. Science 1982;216:518-20.

7 Anderson HA, Lilis R, Daum SM, Selikoff IJ. Asbestosis among household contacts of asbestos factory workers. Ann NY Acad Sci 1979;330:386-99.

8 Langlands JHM, Wallace WFM, Simpson MJC. Insulation workers in Belfast. 2. Morbidity in men still at work. $\mathrm{Br} J$ Ind Med 1971;28:217-25.

9 Copes R, Thomas D, Becklake MR. Temporal patterns of exposure and nonmalignant pulmonary abnormality in Quebec chrysotile workers. Arch Environ Health 1985;40:80-7.

10 Jones RN, Diem JE, Glindmeyer H, Weill H, Gilson JC. Progression of asbestos radiographic abnormalities; relationships to estimates of dust exposure and annual decline in lung function. In: Wagner JC, ed. Biological effects of mineral fibres. Lyon: International Agency for Research on Cancer 1980: 537-43. (IARC sci publ No 30.)

11 Jarvolm B, Arvidsson H, Bake B, Hillerdal G, Westrin C-G. Pleural plaques-asbestos—ill-health. Eur J Respir Dis 1986; 68(suppl):1-59.

12 Finkelstein MM, Vinglis JJ. Radiographic abnormalities among asbestos-cement workers. Am Rev Respir Dis 1984;129:17-22.

13 Rosenstock L, Hudson LD. The pleural manifestations of asbestos exposure. Occupational Medicine: State of the Art Reviews 1987;2:383-407.

14 Britton MG. Asbestos pleural disease. Br J Dis Chest 1982;76: 1-10.

15 Cookson WOC, Musk AW, Glancy JJ. Pleural thickening and gas transfer in asbestosis. Thorax 1983;38:657-61.

16 McGavin CR, Sheers G. Diffuse pleural thickening in asbestos workers; disability and lung function abnormalities. Thorax 1984;39:604-7.

17 Lumley KPS. Physiological changes in asbestos pleural disease. In: Walton WH, McGovern B, eds. Inhaled particles IV. Oxford:
Pergamon Press, 1977:781-8.

18 McMillan GHG, Rossiter CE. Development of radiological and clinical evidence of parenchymal fibrosis in men with nonmalignant asbestos-related pleural lesions. $\mathrm{Br} J$ Ind $\mathrm{Med}$ 1982;39:54-9.

19 Harber P, Mohsenifar Z, Oren A, Lew M. Pleural plaques and asbestos-associated malignancy. J Occup Med 1987;29:641-4.

20 Rogan WJ, Gladen BC, Ragan NB, Anderson HA. US prevalence of occupational pleural thickening - a look at chest $x$-rays from the first national health and nutrition examination survey. $\mathrm{Am} \mathrm{J}$ Epidemiol 1987;126:893-900.

21 Becklake MR. Asbestos-related diseases of the lungs and pleuracurrent clinical issues. Am Rev Respir Dis 1982;126:187-94.

22 Armstrong BK, de Klerk NH, Musk AW, Hobbs MST. Mortality in miners and millers of crocidolite in Western Australia. $\mathrm{Br} J$ Ind Med 1988;45:5-13.

23 Hobbs MST, Woodward SD, Murphy B, Musk AW, Elder JE. The incidence of pneumoconiosis, mesothelioma and other respiratory cancer in men engaged in mining and milling crocidolite in Western Australia. In: Wagner JC, ed. Biological effects of mineral fibres. Lyon: International Agency for Research on Cancer, 1980:615-25. (IARC sci publ No 30.)

24 Major G. Asbestos dust exposure. In: Major G, ed. Proceedings of the first Australian Pneumoconiosis Conference, Sydney, 1968. Sydney: Joint Coal Board, 1968:467-74.

25 Guidelines for the use of ILO international classification of radiographs of pneumoconioses. Geneva: International Labour Office, 1980. (Occupational Safety and Health series No 22.)

26 Cookson W, de Klerk N, Musk AW, Glancy JJ, Armstrong B, Hobbs $M$. The natural history of asbestosis in former crocidolite miners from Wittenboon Gorge. Am Rev Respir Dis 1986;133:994-8.

27 Clayton DG. The analysis of prospective studies of disease aetiology. Communications in Statistics-Theory and Methods 1982;11:2129-55.

\section{Destruction of manuscripts}

From 1 July 1985 articles submitted for publication will not be returned. Authors whose papers are rejected will be advised of the decision and the manuscripts will be kept under security for three months to deal with any inquiries and then destroyed. 